\title{
Compositores chilenos a través de ellos mismos ${ }^{1}$
}

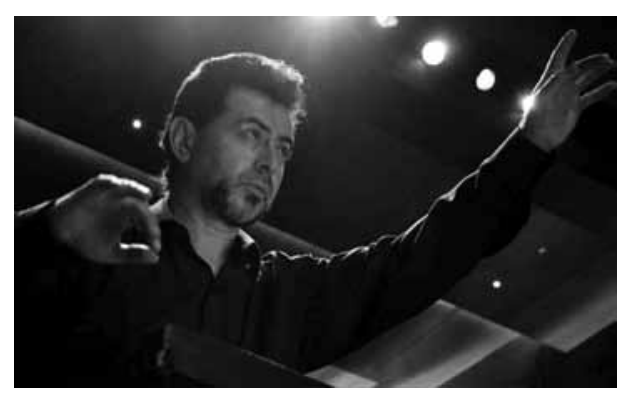

Cáceres Romero, Eduardo (1955)

\section{Epigramas mapuches (1991)}

"Obra escrita el año 1991 por encargo del Ensemble Bartok Chile y estrenada ese mismo año en el Goethe Institut bajo la dirección del compositor y director Samuel Adler (EE.UU.-Alemania). Está escrita para voz contralto, clarinete, violín, violoncello y piano. Son cuatro epigramas basados en textos del poeta mapuche Elicura Chihuailaf en los que expresa su cosmovisión que recoge de la tradición de sus antepasados. Los textos son de carácter místico y aluden permanentemente a aquellos íconos de la cultura mapuche, así como al color azul, los bosques, sus ancestros y la sabiduría de los ancianos.

La música de la obra recoge aspectos primordiales de la música del pueblo mapuche la que es de carácter ritual y no estético. La estética proviene de la integración de ambas músicas en una fusión que considera también la tradición de la música europea occidental del siglo XX.

Esta obra se ha estrenado en más de treinta distintos países por el Ensemble Bartok Chile en sus numerosas giras por el mundo. Además se ha interpretado en más de cien conciertos que incluyen a agrupaciones de cámara de otros países. Ha sido la obra seleccionada como una de las 40 obras mas importantes chilenas del siglo XX en el libro 'Cantus Firmus' ".

With Chop-pin from Schop to Schop up to the Shopp-ing (2009)

"Obra escrita para piano solo. Surgió de cuatro motivaciones centrales para ser compuesta por la admiración que siento por el compositor Frédéric Chopin. La

${ }^{1}$ Los escritos contenidos en esta sección incluyen fragmentos de música en formato digital de las obras a las que hacen referencia, disponibles en www.revistas.uchile.cl, www.revistamusicalchilena. uchile.cl, www.scielo.cl 
primera fue hacer una obra en homenaje al compositor polaco en el 200 aniversario de su nacimiento (2010). Obviamente tenía que ser para piano, instrumento vital y significativo en la obra del compositor. La segunda motivación fue escribir una obra en la que quedara estampada mi admiración por la Balada número 4 en Fa menor del compositor.

La tercera razón fue integrar este pensamiento musical a una idea que venía desarrollando en torno al tango a raíz de mis frecuentes visitas a Buenos Aires. La cuarta razón fue corresponder al pianista Horacio Tardito con esta obra para su disco en homenaje al compositor polaco con estreno en La Serena y Varsovia. La problemática planteada en la integración de estas ideas se resolvió en los elementos comunes encontrados en mi intensa búsqueda de las músicas estudiadas".

\section{Fantasíica araucánica (1987)}

"Obra para piano solo. Integra un ciclo de diecinueve obras para piano condensadas en un libro titulado Fantasías rítmicas en el que se plantean diversas dificultades técnicas progresivas para un estudiante de piano que quiera adentrarse en el estudio de la música pianística del siglo XX. Esta es la obra de mayor dificultad del libro y data del año 1987.

Contiene en su interior un canto extractado de ceremonias del pueblo mapuche que entona la voz soprano del piano y luego canta la voz del bajo. Ese sonido se asocia a una percusión de kultrún sobre la base de un pie rítmico estable vinculado al troqueo en densos acordes y fuertes intensidades. La rítmica en general es estable como una danza ritual, lenta pero profunda.

Esta obra ha sido interpretada por más de diez pianistas de Chile y el mundo. Más de 40 interpretaciones en Europa y América corresponden a la pianista María Paz Santibáñez residente en Francia”.

\section{Alunizaje en el Marga-Marga (2011)}

"Obra escrita por encargo especial de la Orquesta de Cuerdas Marga-Marga que dirige Luis José Recart. Contiene tres movimientos: el primero es una danza basada en rituales ceremoniales del pueblo mapuche, el segundo movimiento es un homenaje al silencio y la intensidad pianissimo que combina en ciertos pasajes con citas a la música de jazz ejecutadas por la orquesta tutti en pizzicato mientras que el tercer movimiento está basado en pasajes del rock de grupos emblemáticos tales como Metallica. Se trata de un pasaje musical desarrollado y ampliado que luego desaparece a través de la eliminación progresiva de sus células rítmicas las que tanto unísono como homofónicamente presentan gran dificultad virtuosística para la orquesta.

Fue compuesta y estrenada el año 2011 en el Edificio Cousiño del DUOC de Valparaíso en el Festival Darwin Vargas de la Universidad Católica de Valparaíso. Luego ha sido interpretada por la misma orquesta en más de veinte ocasiones que incluyen el XII Festival de Música Contemporánea de la Universidad de Chile". 


\section{Cantos ceremoniales para aprendiz de machi $(2004)$}

"Obra compuesta a pedido del Coro Femenino de Cámara de la Universidad Católica de Valparaíso por encargo especial de su director Boris Alvarado. Se trata de tres cantos basados en textos del poeta mapuche Elicura Chihuailaf con alto contenido místico que él recoge de la tradición y de sus ancestros. La obra toma de la cultura mapuche aspectos que son fundamentales en su música tales como los portamentos recurrentes, tanto de subida como de bajada, glissandos microtonales que son permanentes en la atemperancia de rigor y algunos intervalos que los distinguen.

La obra está concebida para coro femenino y algunas solistas. Contiene en su interior aspectos relativos a la iniciación de una machi, además incluye parlatos, sonidos guturales, golpe de palmas y golpes de pie en el suelo. Los procedimientos composicionales son extraídos de la tradición de la música europea occidental y los tres movimientos están estructurados en base a la sección áurea.

Esta obra obtuvo el Premio Altazor 2005 e inauguró los carnavales culturales de ese año del Consejo Nacional de la Cultura y las Artes en la Plaza Sotomayor de Valparaíso. Se ha estrenado en varios países incluyendo Polonia, Perú, Argentina, Uruguay, etc., y se ha interpretado en más de cuarenta conciertos por el Coro Karpatia de la Escuela Universitaria de Música de Montevideo”.

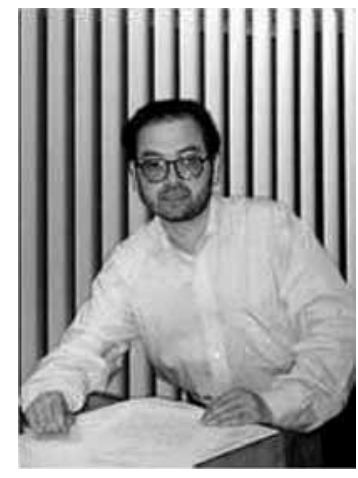

CoRTÉs, RENÁN (1958)

\section{Passacaglia, Choral y Fuguetta (2011)}

“El primer movimiento 'Passacaglia' está estructurado en base a un ostinato variado sobre el cual se construyó un material serial de diferente textura. El segundo movimiento 'Choral' consiste en un fluir más bien estático-homofónico en el piano con un contrapunto rítmico simple en la flauta. El tercer movimiento 'Fuguetta' emplea el mismo material serial anterior en forma imitativa a la séptima. La idea principal de la obra es agotar ciertas posibilidades musicales a través de determinados procedimientos".

\section{Un tren se acerca ;cuidado! (2011)}

"Cuartertino para cuerdas compuesto en 2011 y estrenado el sábado 3 de diciembre de 2011 en el Teatro Universidad de Concepción.

A raíz de una invitación de la agrupación NEO (integrada por algunos músicos de la Orquesta Sinfónica de la Universidad de Concepción) a participar como compositor en un concierto de la temporada 2011, se inició el trabajo a partir de algunas ideas y bosquejos cuyo elemento

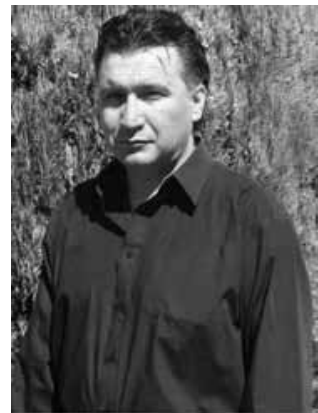

Díaz Pérez, Carlos (1964) 
principal es una melodía en 6/8 del segundo movimiento (de tres) compuesta para la obra de teatro 'Posteridad íntima' de Rodrigo Marquet, realización del Teatro Nacional Chileno el año 1986.

De esta melodía nace el motivo musical de la fuga del segundo movimiento compuesto básicamente en intervalos de cuarta aumentada, para crear una atmosfera tensa y neuróticamente humorística.

Los demás movimientos fueron creados a partir de extractos de masas armónicas del fugato en el segundo movimiento. Se obtienen texturas armónicas muy interesantes y misteriosas que le imprimen ese carácter al primer y tercer movimientos, los que replican el orden de movimientos, lento-rápido y lento de la Sonata para viola y piano de Shostakovich.

Las partes son: I Coral, II Un tren se acerca (fugato), III Llanto.

El título fue puesto por mi hijo Vicente. Al esperar el tren, él exclama - "un tren se acerca ¡cuidado!’. Esta frase me pareció apropiada para titular esta obra”.

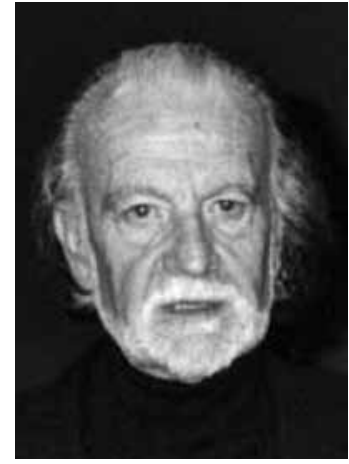

García Arancibia,

FERNANDO (1930)

\section{Rosa perfumada entre los astros (2000)}

"Rosa perfumada entre los astros para contralto, clarinete en Si bemol, violín, cello y piano es una obra compuesta por su autor, especialmente para el Ensemble Bartok Chile, para ser estrenada por dicho grupo musical en el marco de las celebraciones del $600^{\circ}$ aniversario de la Universidad de Cracovia. Según se señala en la partitura, está dedicada al astrónomo Nicolás Copérnico (1473-1543), autor del tratado De revolutionibus orbium caelestium publicado en Nüremberg. Dicho tratado consta de seis libros. En el primero de ellos Copérnico explica su teoría heliocéntrica; en el segundo trata de la geometría del espacio y trigonometría; el tercero está dedicado al movimiento de traslación de la Tierra; el cuarto se refiere a la Luna; el quinto al movimiento de los cinco planetas diferentes a la Tierra, y el sexto trata de las latitudes. El fundamental trabajo del astrónomo polaco fue incluido en 1616 en el Índice de libros prohibidos y, finalmente, borrado del Índice por Paulo IV, en 1758.

En la obra se aprovecha la continua referencia al espacio sideral que el poeta chileno Vicente Huidobro (1893-1948) hace en su poesía, en particular en su poemario Altazor (1931). En la obra Rosa perfumada entre los astros figuran algunos fragmentos del 'prefacio' de ese poema huidobriano, desde donde también surge el título de la obra musical. Los textos de Huidobro que se han utilizado son los siguientes:

Tomo mi paracaídas, y del borde de mi estrella en marcha me lanzo a la atmósfera del último suspiro.

Ruedo interminablemente sobre las rocas de los sueños, ruedo entre las nubes de la muerte. 
Ah, qué hermoso..., qué hermoso.

Veo las montañas, los ríos, las selvas, el mar, los barcos, las flores y los caracoles.

Veo la noche y el día y el eje en que se juntan.

De cada gota de sudor de mi frente hice nacer astros, que os dejo la tarea de bautizar.

Hemos saltado del vientre de nuestra madre o del borde de una estrella y vamos cayendo.

Ah mi paracaídas, la única rosa perfumada de la atmósfera, la rosa de la muerte, despeñada entre los astros de la muerte.

El elemento principal de la obra es el mensaje sonoro que la palabra genera en el compositor y el sentido expresivo que éste le otorga. El factor expresionista se construye desde polos opuestos: la serialización de los materiales, por una parte, y la libre elección de los mismos, por la otra. Esto obliga al intérprete en cada ejecución, desde los primeros ensayos, a integrarse totalmente al discurso propuesto, ya que cada uno de los músicos es responsable de las múltiples versiones finales posibles de la obra, cualesquiera sean ellas".

\section{Canciones de trinchera (2009)}

"Canciones de trinchera, para contrabajo y piano, fue solicitada por el joven contrabajista Jorge Tapia, cuando todavía era estudiante del Departamento de Música y Sonología de la Facultad de Artes de la Universidad de Chile. La razón por la cual el joven me pidió la mencionada composición fue debido a que sentía la necesidad de incluir una obra de autor chileno en el programa del concierto que debía ofrecer para finalizar sus estudios de contrabajo. Como es natural, me sentí honrado con su demanda y dediqué este breve ciclo de piezas para contrabajo y piano 'a Jorge Tapia'. Canciones de trinchera está fechada en 'septiembre de 2009'.

La comentada obra está configurada por tres cortos movimientos. El primero es 'Lento-Rápido-Lento-Rápido'; continúa con un segundo trozo en cuyo encabezamiento se señala 'Lento expresivo', y el tercer movimiento y final es identificado como 'Rápido-Lento, libremente-Rápido'. Los intérpretes deben buscar y encontrar el carácter de las tres piezas en el corto texto de Vicente Huidobro que se cita en la primera página de la partitura, perteneciente al poemario Hallalí. Allí se lee: 'Sobre el cañón/cantaba un ruiseñor/Hermoso blanco es la luna/Todas las estrellas son agujeros de obuses'.

Canciones de trinchera, como muchas otras de mis piezas, se caracteriza por enfrentar conjuntos sonoros de alturas y duraciones claramente establecidas, que se mueven en el universo de la atonalidad, con otros en que tales elementos son determinados libremente por los intérpretes, lo que les obliga a éstos a tener una importante función creativa. En consecuencia, la obra será producto de la capacidad de creación del compositor, del contrabajista y del pianista”. 


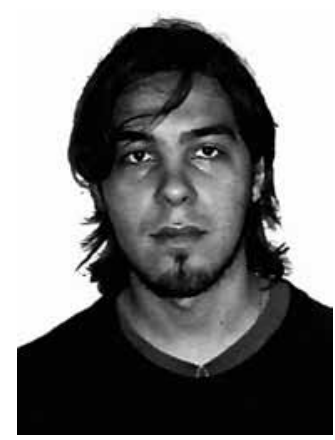

IZQUIERDO KÖNIG, José ManueL

(1985)

\section{Obertura sobre temas valdivianos en estilo de opereta (2011)}

"Obertura sobre temas valdivianos en estilo de opereta fue estrenada aquel día 4 de noviembre de 2011 por la Orquesta Filarmónica Regional de Valdivia bajo la dirección de Genaro Burgos, quien concibió la idea original de esta obra como una fantasía de melodías valdivianas entrelazadas en forma de obertura. Representa el punto cúlmine de una relación de arreglos, orquestaciones y estrenos o reestrenos de música original valdiviana con valor histórico que hemos realizado desde el año 2009, con obras de Roberto Mahler y Guillermo Frick, principalmente. Esa es la razón central de la creación, la cual ya ha sido encargada para ser arreglada y reinstrumentada para otro tipo de agrupaciones, tales como orquestas juveniles o bandas militares. Esto hace eco del uso real de la música en provincia y de la relación personal que ambos tenemos con nuestra ciudad de Valdivia. Está dedicada, por cierto, a don Genaro Burgos”.

\section{Fantasía (1970)}

"Esta obra para ocho instrumentos y voz femenina solista tiene una duración aproximada de 9 minutos.

Fue escrita con motivo de una convocatoria para jóvenes compositores en el Conservatorio Nacional con el fin de dar a conocer las últimas creaciones que se producían en ese período.

A sugerencia del maestro Gustavo Becerra, de quien fuera alumno, fue elegido un conjunto instrumental inusual, con la idea de incursionar en nuevas posibilidades sonoras y sus novedosos efectos a partir de instrumentos bastante disímiles. En general el estilo utilizado hasta entonces

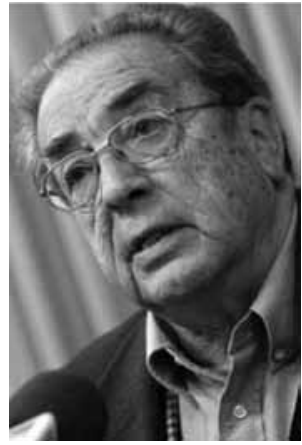

LetElier VALDÉs, Miguel (1939) tal vez adolecía de un cierto acento folclorizante el que, si bien era interesante, de alguna manera estrechaba las posibilidades de ampliar el horizonte estilístico utilizado hasta ese momento.

De cualquier manera, esta obra fue novedosa para su época. El saxofón aporta su insustituible timbre en este conjunto y parece ser del todo acertado su empleo en esta ocasión. La voz femenina está usada como un instrumento más y su papel es una vocalización sin texto.

El estreno lo dirigió el maestro Cirilo Vila y tuvo lugar en 1971 en la sala hoy conocida como Isidora Zegers de la Facultad de Artes de la Universidad de Chile". 
Misa brevis a la memoria de mi madre (2010)

"Esta obra fue compuesta como encargo del Premio Charles Ives 2009 del Instituto Norteamericano de Cultura y la Sociedad Chilena del Derecho de Autor.

Está estructurada en cuatro partes -Kyrie, Gloria, Sanctus y Agnus Dei- y fue dedicada a la memoria de mi madre, Q.E.P.D.

La obra está escrita para soprano solista, coro femenino y orquesta de cuerdas. En su desarrollo se encuentran diversas maneras de enfrentar el sonido desde las sonoridades modales, la tonalidad, la atonalidad, los clusters orquestales y corales. Al mismo tiempo se encuentran

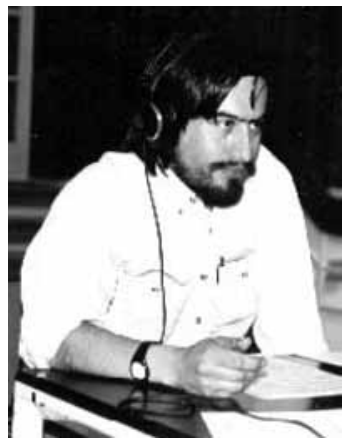

Zamora, CARLOS (1968) sonoridades pentáfonas y ritmos que rememoran los rituales mapuches.

La obra se estrenó en el XX Festival de Música Contemporánea de la Universidad Católica de Chile, el día 14 de noviembre de 2010 en el Centro Cultural Gabriela Mistral. Sus intérpretes fueron la soprano Cecilia Barrientos, el Coro Femenino de Santiago, la Orquesta de la Provincia Marga Marga, todos dirigidos por el propio compositor, Carlos Zamora.

El 6 de agosto de 2011 fue interpretada por el Coro y Orquesta de la Universidad de Concepción bajo la dirección del propio compositor”. 